\title{
The Role of Learning Styles in the Success of TBLT in EFL Classrooms in Saudi Arabia
}

\author{
Badia Hakim \\ English Language Institute, King Abdulaziz University, Jeddah, Kingdom of Saudi Arabia \\ E-mail: badiahakim82@gmail.com
}

Received: 18-10- 2014

Published: 01-05- 2015
Accepted: 10-01- 2015

doi:10.7575/aiac.ijalel.v.4n.3p.205
Advance Access Published: January 2015

URL: http://dx.doi.org/10.7575/aiac.ijalel.v.4n.3p.205

\begin{abstract}
Despite the recognition of Task-Based Language Teaching (TBLT) in English language learning classes in different contexts, its successful implementation in EFL contexts has attracted insufficient attention. As an offshoot of communicative language teaching, TBLT can provide EFL language learners with ample opportunities to embark on using language for more communicative purposes through interaction and engaging in collaborative tasks. The present study adopts an action research approach to implementing TBLT in a traditional language learning context at a major international university in Saudi Arabia. In particular, it intends to determine the students' $(N=25)$ learning styles using Felder-Silverman Learning Style Model (FSLSM) and to use varying tasks to tackle the common learning problems such as lack of participation in learning activities and low motivation. The analysis of data from different data collection instruments revealed that applying TBLT approach in this context helped students enhance their interaction with their classmates and teacher and used English for more authentic purposes while performing a series of learning tasks. In addition, the implementation of TBLT in this context motivated students to engage in different learning activities. At the end, implications of the findings for further research are discussed.
\end{abstract}

Keywords: TBLT; FSLSM; action research; EFL; Saudi Arabia

\section{Introduction}

As there is a high demand for learning and knowing English for different purposes in the new era of globalization, the need to cater for the real learning needs of students has led to the integration of more social constructivist approaches in language education programs. With the paradigm shift of student-centered pedagogy (East, 2012), task-based instruction has attracted a plethora of research and practice in English as a second or foreign language contexts since 1980s. It has now made inroads into language learning syllabi, classroom teaching and assessment in different language learning programs (Nunan, 2006). Among its well-recognized benefits, task-based approach to language learning has the potential to enhance learners' communicative skills, introduce authentic instructional texts and activities in the classrooms, provide opportunities for meaningful interaction and learning, and increase learners' involvement in the learning process (Ellis, 2003; Nunan, 2006; Willis \& Willis, 2009).

Although literature on TBLT abounds with studies on its scope, benefits, challenges, and implications for its implementation in different contexts (Ellis, 2000; Littlewood, 2004, 2007; McDonough \& Chaikitmongkol, 2007; Nunan, 2004, 2006; Van den Branden, 2006; Willis \& Willis, 2007), there is scarcity of research conducted in EFL contexts such as Saudi Arabia. In order to contribute to the literature on TBLT research in this context, the current study was conducted with an aim to investigate the interface between implementing TBLT and EFL language learners' learning styles.

\section{Literature review}

\subsection{Task-based Language Teaching (TBLT)}

TBLT has been defined and conceived by different practitioners and teachers in different contexts (Nunan, 2000), yet it generally "refers to an approach based on the use of tasks as the core units of planning and instruction in language teaching" (Richards \& Rodgers, 2001, p. 223). Previously, Prabhu (1987) defined a task as "an activity which required learners to arrive at an outcome from given information through some process of thought, and which allowed teachers to control and regulate that process" (p. 24). Based on these definitions, different designs have been proposed to implement a task-based lesson in language learning classes (see Prabhu 1987; Willis 1996). For example, Willis (1986) divided a task-based lesson into three main stages of 'Pre Task', 'During Task' and 'Post Task'. During the 'Pre Task' stage, teachers and students are engaged in undertaking activities to prepare for the next step or 'During Task'. These could include goal setting, planning about the time, and perhaps doing a similar task. The second step or 'During Task' phase is concerned with students' actual engagement in carrying out the task. The 'post Task' generally centers around the evaluation of students' performance and performing conscious raising activities to make sure students achieved the learning outcomes. Skehan (1998) further believed that a task should have five key characteristics: 
"(a) meaning is primary, (b) learners are not given other people's meanings to regurgitate, (c) there is some sort of relationship to comparable real-world activities, (d) task completion has a priority, and (e), the assessment of tasks are done in terms of outcome”. (p. 147)

Robinson et al. (2009) also proposed a model of the more inclusive categories of task characteristics that incorporated task complexity or cognitive factors, task condition or interactive factors, and task difficulty that are relevant to the learner factors. These parameters vividly suggest that a task-based lesson should focus primarily on learning and the importance of meaning rather than focus on form or what traditional teaching methodologies used to emphasize. These tasks should be then related to the real-life occurrences or at least bear a resemblance to the real situations. Furthermore, the tasks should focus on the goal set at the pre-task phase and their assessment should be consequently based on how well students complete them.

From a theoretical perspective, the popularity of task-based teaching seems to be a reaction to the PPP approach model (presentation, practice, production) where teachers presented a new lesson first and then gave students enough time to engage in completing the drills or exercises before producing the new learned lesson in the spoken or written form. Task-based learning appears to be an upside down version of PPP whereby students begin with the third stage and engage in the producing the language. The teacher's role is periphery, cooperating only with goal-setting and the stage in which students should be aware of new forms, structures or patters of language use or usage at the end. In other words, students are in control of their learning and teacher's role is of a facilitator or monitor to make sure the outcome has been achieved successfully. Also, teachers need to design interactive tasks that motivate students to work together and participate in meaningful interactions.

However, research has also provided evidence against the effectiveness of TBLT for several contexts as well as different types of learners (Burrows, 2008; Carless, 2002; Hu, 2005; Littlewood, 2007; Sato, 2009; Swan, 2005). As far as EFL classrooms are concerned, students may use code-switching and focus mainly on form rather than meaning because of their low level of English proficiency and the difficulty of teachers to create or mock the context in which the target language should be used (Carless, 2002; Sato, 2009). In particular, Swan (2005) argued for the difficulty of applying Task-based learning in classes with lower level of English proficiency, such as beginner and elementary classes. Additionally, Sato (2009) contended that TBLT could not be a strong alternative to the traditional PPP models of instruction in the contexts where students are pre-occupied with preparation for exams, may not use the target language for real-life purposes, and are not exposed to too much L2 input.

\subsection{Learning styles}

There is no doubt that individuals learn in different ways. That is, they have their own styles of learning, retaining, and retrieving of information, which refer to their learning styles. These learning styles seem to be inherent characteristics by which individuals deal, in terms of perceiving, interacting and responding, with the flow of information they constantly receive from the environment. Kinsella (1995, p. 171) defined learning styles as "an individual's natural, habitual, and preferred ways of absorbing, processing, and retaining new information and skills." These characteristics are highly important when it comes to learning another language. That is, students' learning styles are different from each other and language educators are expected to take these similarities and differences into account to enhance the productivity of their instruction, to help students know how they can learn better, and to match their expectations and instruction with those of their students. Indeed, learning styles can affect the extent to which students pick up their learning strategies or even the way they view the instructional activities. For example, adult learners might link the learning tasks to their life experiences, prefer problem-solving learning strategies and meaningful learning tasks, and be in charge of their learning (Brookfield, 1990; Knowles, 1998). Different scholars has thus far proposed and examined different classifications on learners' learning styles. However, one of the most cited indexes of learning styles was developed by Soloman and Felder (1999), which is known as 'The Index of Learning Styles Questionnaire'. This inventory includes 44 items addressing 8 types of learning styles in four dichotomies of active/reflective, sensitive/intuitive, visual/verbal and global/sequential.

As far as implementing task-based instruction or learning is concerned, its success might depend on many factors. One of these influential factors is language learners' learning styles. Oxford (2001) argued that learning styles might have an effect on the type of strategies learners choose to accomplish a given or assigned task. Since learning strategies are "any sets of operations, steps, plans, routines used by the learner to facilitate the obtaining, storage, retrieval, and use of information" (Wenden \& Rubin, 1987, p. 19), they could be affected by these inherent characteristics. As Oxford (2001) argued, learners with an extroverted learning style, for example, might find face-to-face communication tasks more interesting and easier than learners with an introverted learning style. This is also true about those learners with analytic and intuitive learning styles, as their preferences on participating in different focus-on-form or focus-on-forms tasks (Norris, \& Ortega, 2000) could considerably vary.

The current study aims to firstly evaluate the effectiveness of the implementation of TBLT in an EFL language learning class and secondly to identify students' learning styles in order to better match the designed learning tasks to their preferences and expectations. This study is significant in that tailoring instructional tasks to students' learning styles can enliven classroom collaborative tasks of pair and group work, which are not common in this context and they are implemented in a different manner.

\subsection{Research Questions}

This study was guided by the following three research questions: 
1. To what extent is investigating students' learning styles effective for the implementation of TBLT?

2. What are students' opinions on the effectiveness of TBLT in their language learning classes?

3. What is the teacher's perception of the effectiveness of TBLT in her language learning classes?

\section{The study}

\subsection{Participants}

This study was conducted at the English Language Institute (ELI) at King Abdulaziz University (KAU) in Saudi Arabia. Students from an intact English language classroom were selected to participate in this study. They were 25 Saudi female students who came from different parts of the country; hence spoke Arabic as their first language. Since the medium of instruction in this university is English, students attend intensive language classes in order to be prepared to deal with the disciplinary texts and communicate in this language at different departments or programs. The textbook taught to these participants was New Headway Plus special edition published by Oxford University Press, a series that were used for all proficiency levels at this institute. The researcher was involved in teaching this group of students. The average mean age of students was 18.5 .

\subsection{Data collection}

The following data collection instruments were selected based on their potential to respond to the research questions:

- TBLT lesson plan.

- FSLSM questionnaire distributed on the second during the first week of the module.

- Students' diaries kept during the second week to the sixth week of the module.

- Teacher' diary kept from the first week to the sixth week of the module.

- Tasks evaluation questionnaires distributed during the second and last week of the module.

Questionnaires were used as data collection instruments because they are a reliable source of gathering data and the repetitive response from the participants to the same questions increases the reliability of the data collected (Munn \& Drever, 1990). In addition, diaries were used because they include insights of actions (McDonough, 1994). A diary could also be an important research tool that contains observation, feelings, reactions, interpretations, hunches and explanations of the students and teachers (Elliot, 1991).

\subsection{Data analysis}

FSLSM questionnaire: A modified and simple version of FSLSM index with 26 statements, which were translated in Arabic, was distributed in the class on the second day of the first week in order to find out about the students' learning styles. Students were given three options (A, B, or C) for each statement to tick. In other words, they were supposed to tick ' $A$ ' if the statement applied to them, tick ' $B$ ' if the statement was sometimes true, and tick ' $C$ ' if the statement was never true. Students' responses to the items on this questionnaire were analyzed and tabulated for each learning style.

Teacher and students' diaries: Diaries written by students and the teacher were analyzed in order to achieve three objectives:

- To identify the cohesion and reliability of common factors in the feedback from the learners and the teachers.

- To gauge the level of learning that took place and is reflected from the teacher and students' statements about the variety of tasks.

- $\quad$ To identify and analyze the stage-by-stage comments made for each task in terms of their potential to add new dimensions to students' learning experiences.

The attempt was also made not to reveal the participants' identity and to maintain the confidentiality of their responses. As such, diaries were named as X, Y and Z. moreover, the results from the analysis of the diaries were used to support the findings from the other data collection instruments. That is, they were used to cross-check the findings from other resources.

Task Evaluation Questionnaires: These surveys included two different questionnaires administered to evaluate the different stages of the implemented learning tasks used in this study.

Questionnaire A: There were 10 statements on this survey, and it was administered at the beginning of the module during the second week. The purpose of the questionnaire was to evaluate the Pre Task phase without piloting TBLT. Students were given 5 options to tick on a rating scale from 'strongly agree (1)' to 'strongly disagree (5)'.

Questionnaire B: There were 16 statements on this survey, and it was administered at the end of the module on the fourth day of the sixth week. The purpose of this survey was to evaluate During Task phase after piloting TBLT. Students were given 5 options to tick on a rating scale from 'strongly agree (1)' to 'strongly disagree (5)'.

\section{Findings and discussion}

Table 1 shows the results from the analysis of FSLSM questionnaire or learning styles index. According to this table, more than half of the participants (52\%) reported having a kinesthetic/tactile learning style. The second most common learning style among students was visual style (28\%), followed by auditory $(20 \%)$ learning style as the last reported style. 


\subsection{Analysis of FSLSM questionnaire}

Table 1. Questionnaires were collected and the data was analyzed as follows.

\begin{tabular}{lll}
\hline Number of students $(\mathrm{N}=25)$ & Learning style & $\%$ \\
\hline 13 & Kinesthetic/Tactile Learners & $52 \%$ \\
7 & Visual learners & $28 \%$ \\
5 & Auditory learners & $20 \%$ \\
\hline
\end{tabular}

\subsection{Analysis of students' diaries}

The results from the students' diaries showed that they were quite satisfied with the selected tasks. Stage-based reports indicated that the assigned tasks were according to students' learning styles, added variety to the classroom activities, and were helpful to improve their learning.

\subsubsection{Adding variety to learning tasks}

Aligned with Willis's (1996) theory of task-based learning, more interaction was noticed among students while they worked in groups. Students had valuable remarks about almost all the tasks, and they showed their satisfaction with the implemented TBLT approach. Willis (1996) also suggested that motivation level would increase if the tasks were selected carefully according to learners' needs and preferences. Throughout the study, there were some tasks that were about guessing the meaning of the newly introduced lexical items with the help of pictures, realia and CCQs. Analysis of the students' diaries showed that teaching contextualized vocabulary with clues was highly effective and was one of the motivating tasks. Students also acknowledged the 'use of video clip as a pre-reading task, which helped them make better sense of the reading passages. As another effective learning strategy and appealing task, students' mentioned the positive impact of group discussion. Previous research (e.g., Lightbown \& Spada, 1993) also supported this finding, suggesting that some learners feel motivated by learning through physical actions. Similarly, students referred to the positive impact of pair and group work on facilitating their language learning because they could easily share their learning problems and engage in scaffolding activities.

\subsubsection{Adding quality to learning experiences}

While carrying out a task, students felt the need to concentrate on the topic and accordingly improve their learning. For example, in order to perform a role-play, they read the instructions in detail. Willis (1996) also asserted that students should react to the content and process the text for meaning in order to achieve the learning goals. The results from the content of diaries clearly indicated that tasks focusing on teaching vocabulary were specifically effective when new lexical items were taught with the help of a video clip or an audio track. This trend led to a more productive and enduring learning for students.

\subsubsection{Improving the classroom atmosphere}

The results indicated that students noticed and acknowledged the change in the type of activities they engaged in and in the classroom atmosphere after the introduction of TBLT. These changes were felt when the teacher started to use a variety of tasks such as group discussions and role-plays.

\subsubsection{Enhancing opportunities for interaction}

A common complaint from students before the implementation of TBLT was their dependence on the textbooks and lack of student-centered or student-initiated activities. At the beginning of the semester, students' level of satisfaction with the techniques used in their class was very low. However, during the course of the semester and when they were acquainted with the idea of TBLT, they gradually demonstrated more approval of the lessons, which increased their motivation and enhanced their opportunity for more interaction and communication in the classroom.

\subsection{Analysis of the teacher's diary}

\subsubsection{Engaging in self-reflection for the professional development}

I could easily figure out from my teaching diary that TBLT approach led to a positive change in my teaching style. These changes could be summarized as follows:

1. Student-centered teaching approach added more diversity to the activities I implemented in the class. My students were motivated as they were the driving force behind the learning process in the class.

2. I was able to prepare my lessons more efficiently and this gave me a sense of achievement after delivering each lesson. Lesson plans offered me a clear road map to enhance my students' learning.

3. Self-reflection assisted me to learn from my own mistakes and improve my subsequent instruction.

Reflective diaries are the great source of self-awareness, having a major role in teaching more effectively. Diaries provided an opportunity to think critically about my performance and help to self-evaluate the performance without any rating scale. Reviewing my diary gave me an opportunity to figure out the strong and weak areas of my instruction. Likewise, I could select the effective teaching strategies and improve those areas that were more problematic for students. 


\subsubsection{Establishing rapport with students}

TBLT approach introduced the idea of student centeredness and increased student's talk time in the class, which, in turn, improved the teacher-student rapport. According to Willis (1981), this sense of friendliness can enhance the quality of the learning process. In addition, the established rapport with my students helped them gain more selfconfidence and share their ideas freely, which, in the long run, boosted their motivation.

\subsubsection{Adopting a learner-centered teaching style}

TBLT implementation brought a major change in the teaching style. Introduction of various student-centered tasks virtually minimized the teacher's dominance in the classroom. The variety and the diversity of the tasks increased students' interest level, as I adopted the role of facilitator helping students with their learning problems and challenges, in particular when they were working together.

\subsubsection{Acknowledging the importance of having a lesson plan}

The use of a lesson plan can offer teachers an opportunity to become more organized and prepared (Waters, 1988). As such, I was able to reflect on my mistakes on a daily basis and improve them with the passage of time. Preparation of my lesson plans increased my self-confidence as a teacher and gave me courage to introduce more innovative tasks in my class. Having a great 'Lead in' during the 'Pre Task' stage was still another significant factor that leveled up my students' engagement in the instructional activities.

\subsection{Analysis of tasks evaluation questionnaires}

\subsubsection{Efficacy of questionnaire A (Pre Task phase) and questionnaire B (During Task Phase)}

The results from the analysis of students' responses to both questionnaires, or Pre Task and During Task surveys, revealed that students were satisfied with both stages of task-based instruction. This is further evident in the results from the analysis of students' responses to questionnaire A (Table 2).

Table 2. The results of students' responses to questionnaire A.

\begin{tabular}{lllllll}
\hline & $5 \mathrm{SA}$ & $4 \mathrm{~A}$ & $3 \mathrm{U}$ & $2 \mathrm{D}$ & $1 \mathrm{SD}$ & Mean \\
\hline Task 1 & $8 * 5=40$ & $8 * 4=32$ & $5 * 3=15$ & $3 * 2=6$ & $1 * 1=1$ & 18.8 \\
Task 2 & $7 * 5=35$ & $6 * 4=20$ & $4 * 3=12$ & $5 * 2=10$ & $3 * 1=3$ & 16.0 \\
Task 3 & $6 * 5=30$ & $7 * 4=28$ & $5 * 3=15$ & $5 * 2=10$ & $2 * 1=2$ & 17.0 \\
\hline
\end{tabular}

In particular, the results from questionnaire A revealed that while students were not satisfied with the Pre Task stage at the beginning of the module, they were satisfied with their learning experiences after the implementation of TBLT, as measured by questionnaire B as well. Moreover, the results from questionnaire A indicated that majority of students found the following strategies difficult or tiresome:

1. Individually looking for minor details and synonyms in a given passage was difficult.

2. Sitting at one place and reading through the textbook was boring.

On the other had, the results from questionnaire B demonstrated that students appreciated three types of tasks as follows:

1. Guessing the new vocabulary items with clues, pictures and CCQs.

2. Finding the most suitable pattern of information sharing during jigsaw reading.

3. Completing a closed text with the audio track listening.

\section{Conclusions}

This study provided evidence that TBLT approach improved students' classroom performance and increased their motivation for further learning. Not only did implementing this approach in this context affect students' learning experiences, but it also had a positive impact on enriching the teacher's teaching experiences. The findings also suggested that implementing TBLT in this EFL context enhanced students' satisfaction with different instructional tasks and motivated them to work harder and use the target language in their interaction while participating in collaborative tasks of pair and group work. Furthermore, the results of this study espoused the integration of more elements of student-centered approaches in English language programs where conventional teacher-centered pedagogical approaches are still used. As an example, students preferred to, for example, watch a video clip before reading the assigned task over the traditional 'look for the main idea' or 'reference questions' types of activities.

Change in the teaching style brought a major change in the overall learning atmosphere of the classroom and students became more familiar with the task-based learning approach. Another positive change was the established rapport between students and the teacher that was clearly reflected in the diaries. Students felt more comfortable with the teacher, which helped students share their learning challenges and problems through dialogues and discussions with the teacher. The implementation of TBLT assigned the teacher a new role. The teacher was no longer the presenter of the 
lesson, but a facilitator who was involved in the process during the pre and post task phases. Monitoring students' work helped the teacher learn from the likely pedagogical malpractices and, as a result, find ways to improve her instruction.

\subsection{Implications for further research and practice}

This study could contribute to the literature on TBLT in EFL contexts. The results of this study suggest that more student-centered approaches to language teaching can motivate language learners to improve their performance and, on the other hand, inform teachers of the need for professional development by practicing self-reflection and selfevaluative activities as well as subscribing to more effective teaching approaches that can compensate for students' lack of exposure to the target language. Furthermore, the findings imply that teachers' selection or development of teaching materials and tasks can help motivate students for more engagement in the learning process or otherwise demotivate them for more withdrawal from participating in the learning tasks because, as Alwright and Bailey (1991) suggested, the use of ineffective teaching methodologies can switch learners off. That is, language teachers should put in more time and effort into selecting those tasks that can cater for the needs of students with different learning styles and preferences. Thus, matching instructional approaches and strategies to students' learning styles can enhance their intake of the teaching materials, motivate them, and affect their attitudes towards the lesson.

However, as previous research (e.g., Burrows, 2008; Carless, 2002; Hu, 2005; Littlewood, 2007; Sato, 2009; Swan, 2005) indicated, teachers may encounter challenges if they are interested in designing appropriate instructional materials and creative strategies recommended by TBLT. In order to overcome some of these challenges, teachers can resort to the use of technological advances in designing learning environments rich in their potential to help learners with different learning styles benefit from learning experiences. Moreover, teachers' awareness of TBLT is inevitable in order to introduce the idea of adaptability and flexibility in their teaching practices. While introducing TBLT approach, all language teachers should focus on the selection of more user friendly, enjoyable, and student-centered tasks because students' progress, their attitudes towards the class activities, and their success are directly influenced by the types of the tasks teachers design, select, or prepare. In contrast to the conventional style of teaching, TBLT turns the language learners into active participants who were passive listeners during PPP model of instruction. TBLT approach can help teachers communicate the course requirements and their expectations of their students. On the other hand, students may also contribute when teachers go through the process of selecting learning tasks. Introducing appropriate tasks can enhance students' talking time and improve their speaking and communicative skills. The design of these tasks can also affect the classroom environment. As an example, interactive tasks can offer students more learning opportunities. This requires teachers, however, to reflect on their skills and teaching practices because self-reflection is regarded as an opportunity to improve and strengthen their professional development skills. As Wallace (1991) mentioned, teachers should always refresh their existing knowledge.

While different obstacles such as crowded classes, inappropriate resources, lack of training on the part of teachers and confidence in language use, and traditional pedagogical approaches hamper the implementation of TBLT in EFL classrooms (Carless, 2002; Sato, 2009; Hu, 2005; Burrows, 2008; Littlewood, 2007), the benefits of implementing this approach could way outweigh the problems involved, as there is high demand for learning English specially in EFL contexts where competency in English language has become an asset in different spheres of the daily life.

The current study, however, suffers from a number of limitations. First of all, the sample size was small and students from one class were selected as the participants. More studies are needed to investigate the interface between TBLT and learners' learning styles with a bigger population of students in different EFL contexts in order to be able to generalize the findings to such contexts. As another difficulty in designing or selecting tasks in many language learning programs is the mismatch between teachers and students' beliefs and attitudes towards such tasks. Thus, future research on TBLT in this context might need to investigate the similarities and differences between students and teachers' attitudes towards task-based learning (Carless, 2002).

\section{References}

Allwright, D., \& Bailey, K. B. (1991). Focus on the language classroom. Cambridge: Cambridge University Press.

Brookfield, S. D. (1990). The skillful teacher. San Francisco, CA: Jossey-Bass.

Burrows, C. (2008). Socio-cultural barriers facing TBL in Japan. The Language Teacher, 32(8), 15-19.

Carless, D. (2002). Implementing task-based learning with young learners. ELT Journal, 56(4), 389-396.

Carroll, M. (1994). Journal writing as a learning and research tool in the adult classroom. TESOL Journal, 4(1), 19-22.

Cohen, I. \& Manion, L. (1980). Research methods in education. New York: Routledge.

Cook, V. (1996). Second language learning and teaching. London: Edward Arnold.

Davies, R. (1993). Chronicles: Doing action research: The stories of three teachers. Reconstructing teacher education. London: The Falmer Press.

East, M. (2012). Task-Based Language Teaching from the Teachers" Perspective. Amsterdam: John Benjamins B.V.

Ellis, R. (2000). Task-based research and language pedagogy. Language Teaching Research, 4(3), 193-200.

Ellis, R. (2003). Task-based Language Learning and Teaching. Oxford: Oxford University Press. 
Hu, G. W. (2005). Contextual influences on instructional practices: a Chinese case for an ecological approach to ELT. TESOL Quarterly, 39, 635-660.

Kinsella, K. (1995). Understanding and empowering diverse learners in the ESL classroom. In J. Reid (Ed.), Learning styles in the ESL/EFL classroom (pp. 170-195). Boston, MA: Heinle \& Heinle.

Knowles, M. S. (1998). The modern practice of adult education: From pedagogy to andragogy. Englewood Cliffs, NJ: Prentice Hall Revised and Updated.

Lightbown, P. M., \& Spada, N. (1993). How languages are learned. Oxford: Oxford University Press.

Littlewood, W. (2004). The task-based approach: Some questions and suggestions. ELT Journal, 58(4), 319-326.

Littlewood, W. (2007) Communicative and task-based language teaching in East Asian classrooms. Language Teaching, 40, 243-249.

McDonough, Jo. (1994). A teacher looks at teacher's diaries. ELT Journal, 42(1), 14-20.

McDonough, K., \& Chaikitmongkol, W. (2007). Teachers' and learners' reactions to a task-based EFL course in Thailand. TESOL Quarterly, 41, 107-132.

Munn, P., \& Drever, E. (1990). Using questionnaires in small-scale research. A teacher's guide. Edinburgh: The Scottish Council for Research in Education.

Norris, J. M., \& Ortega, L. (2000). Effectiveness of L2 instruction: A research synthesis and quantitative meta-analysis. Language Learning, 50, 417-528.

Nunan, D. (1989). Designing tasks for the communicative classroom. Cambridge: Cambridge University Press.

Nunan, D. (2004). Task-Based language teaching. Cambridge, UK: Cambridge University Press.

Nunan, D. (2006). Task-based Language Teaching in the Asia Context: Defining 'Task'. Asian EFL Journal, 8(3), 1218.

Oxford, R.L. (2001). Language learning styles and strategies. In M. Celce-Murcia (Ed.), Teaching English as a second language (pp. 359-366). Boston: Heinle \& Heinle.

Prabhu, N .S. (1987). Second language pedagogy. Oxford: Oxford University Press.

Richards, J. C., and Rodgers, T. (2001). Approaches and Methods in Language Teaching (2nd Ed.). Cambridge: Cambridge University Press.

Robinson, P., T. Cadierno, and Y. Shirai. (2009). Time and motion: Measuring the effects of the conceptual demands of tasks on second language speech production. Applied Linguistics 30, 533-544.

Sato, R. (2009) Suggestions for creating approaches suitable to the Japanese EFL environment. The Language Teacher, 33(9), 11-14.

Soloman, B. A., \& Felder, R. M. (1999). The index of learning styles. Retrieved January 6, 2015, from http://www4.ncsu.edu/unity/lockers/users/f/felder/public/ILSdir/ILS-a.htm

Swan, M. (2005) Legislation by hypothesis: the case of task-based instruction. Applied Linguistics, 26(3), 376-401.

Van den Branden, K. (ed.) (2006). Task-based language education: From theory to practice. Cambridge: Cambridge University Press.

Wallace, J. M. (1991). Training language teachers. Cambridge University Press: Cambridge.

Waters, A. (1988). Teacher-training course design: A case study. ELT Journal, 42(1), 14-20.

Wenden, A. L., \& Rubin, J. (1987). Learner strategies in language learning. Englewood Cliffs, NJ: Prentice Hall.

Willis, D. \& Willis, J. (2007). Doing Task-based Teaching. Oxford: Oxford University Press.

Willis, D. \& Willis, J. (2009). Task-based language teaching: some questions and answers. The Language Teacher, 33(3), 3-8.

Willis, J. (1981). Teaching English through English. London: Longman.

Willis, J. (1996). A framework for task-based learning. Harlow: Longman. 